\title{
Groundwater-induced vertical movements in Tsukuba revisited: installation of a new GPS station
}

\author{
Hiroshi Munekane, Yuki Kuroishi, Yuki Hatanaka, Kazuhiro Takashima, and Masayoshi Ishimoto \\ Geospatial Information Authority of Japan, Tsukuba, Ibaraki, Japan
}

(Received July 2, 2010; Revised August 4, 2010; Accepted August 5, 2010; Online published December 13, 2010)

\begin{abstract}
A new continuous GPS station, 06S061, was installed in Tsukuba, Japan, which is directly anchored to the soil at a depth of $190 \mathrm{~m}$, so that it is less affected by seasonal poroelastic deformations of aquifers induced by groundwater extraction for irrigation. A comparison of GPS-derived vertical movements of surrounding GPS stations relative to $06 \mathrm{~S} 061$ with the independent observations revealed that $06 \mathrm{~S} 061$ has an observation quality comparable to a standard GPS station in terms of coordinate repeatability. The poroelastic deformations of aquifers below $190 \mathrm{~m}$ recorded at 06S061 were estimated to have peak-to-peak values of about $1 \mathrm{~cm}$, which is half of the total poroelastic deformations of aquifers observed at surrounding GPS stations.
\end{abstract}

Key words: GPS station, Tsukuba, vertical deformations, aquifers, poroelasticity.

\section{Introduction}

Anomalous seasonal vertical movements that have peakto-peak values of $2 \mathrm{~cm}$ are observed from the space geodetic stations at the Geospatial Information Authority of Japan (GSI), Tsukuba, Japan. Tobita et al. (2004) and Munekane et al. (2004) have investigated these movements in detail and found that they are closely associated with the groundwater level changes that occur due to groundwater pumping for irrigation of the surrounding rice elds. Munekane et al. (2004) proposed a model in which the vertical movements are driven by the poroelastic deformations of the aquifer, and such movements have been successfully explained using this model.

The GPS stations at GSI have been playing an important role in the national geodetic network. One of the stations, TSKB, which is registered at the International GNSS Service (IGS), is used in the realization of the International Terrestrial Reference Frame (ITRF) (e.g. Altamimi et al., 2007), and 92110 has been used as a reference site in the routine GPS analysis at GSI. Hence, it is desirable to have a GPS station that is less affected by the seasonal vertical movements and could be used as a control station for monitoring these movements at these GPS stations at GSI.

A new continuous GPS station, 06S061, was installed at GSI in April 2007. The station is expected to be less affected by the seasonal vertical movements since its antenna is mounted on the extension of the inner tube of the subsidence meter, a device for measuring surface deformations, which is directly anchored into the soil at a depth of $190 \mathrm{~m}$.

The initial examination of the vertical coordinate time series of 06S061 showed that the station is severely affected by unknown noises that amount to a little less than $1 \mathrm{~cm}$. We

Copyright (C) The Society of Geomagnetism and Earth, Planetary and Space Sciences (SGEPSS); The Seismological Society of Japan; The Volcanological Society of Japan; The Geodetic Society of Japan; The Japanese Society for Planetary Sciences; TERRAPUB.

doi:10.5047/eps.2010.08.001 have identi ed the noise sources, which are: 1) multipath from the roof of the subsidence observatory that houses the station, and 2) water droplets formed inside the radome in winter due to condensation in the air inside the observatory (Munekane et al., 2009). The station was subsequently refurbished to overcome the aforementioned problems and resumed observations in March 2009.

In this article, we will rst compare the GPS-derived vertical movements relative to the refurbished station with independent observations. We then evaluate the reduction in anomalous seasonal vertical movements at 06S061 compared to those at surrounding GPS stations using the GPSderived absolute vertical deformations.

\section{Subsidence Monitoring at GSI}

Station 06S061 was installed in the subsidence monitoring observatory at GSI (Fig. 1(a)), which houses the subsidence meter. The station is located within a few hundred meters of other GPS stations. A Trimble choke-ring antenna (TRM29659.00) and a Trimble 5700 receiver are used for observation.

The antenna of 06S061 is attached to the extension pipe of the inner tube (Fig. 1(b)) of the subsidence meter so that the antenna is xed in the soil at a depth of $190 \mathrm{~m}$. The pipe is made of carbon ber-reinforced plastic (CFRP), which was selected due to its high strength as well as low thermal expansion coef cients $\left(\leq 1 \times 10^{-6} /{ }^{\circ} \mathrm{C}\right)$. In order to mitigate the noise caused by multipath from the roof and water droplets formed inside the radome (Munekane et al., 2009), we raised the antenna $1 \mathrm{~m}$ above the roof and covered the roof with a radio wave absorber sheet (Fig. 1(b) and (c)). We replaced the radome by a SCIGN radome to mitigate its impact on the antenna phase center.

Apart from the observations of the subsidence meter and GPS, monthly leveling has been conducted to measure height changes of GPS stations 92110 and 960627 with respect to the reference point marked on the inner tube of the 
a)

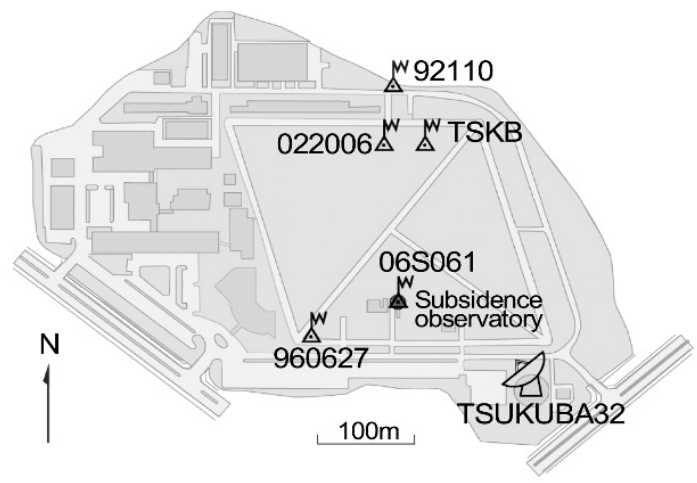

b)

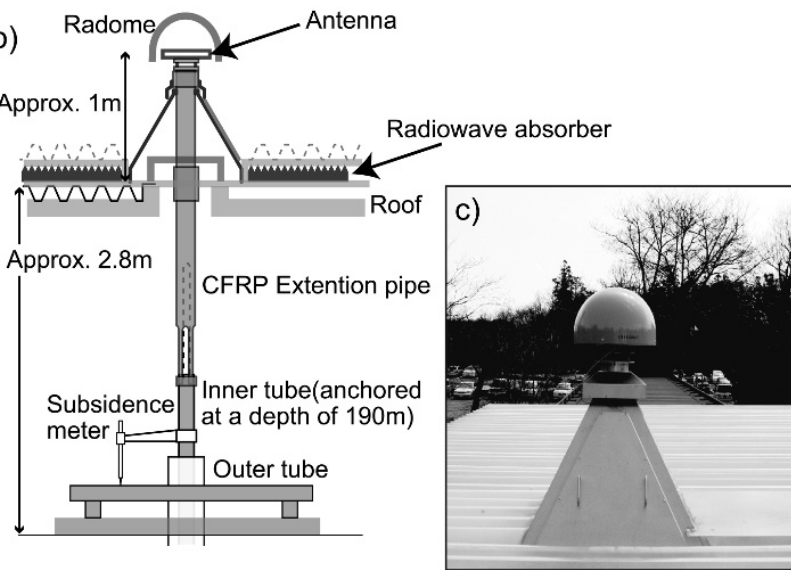

Fig. 1. (a) Location of GPS station 06S061, other GPS stations, and the VLBI station in Tsukuba. (b) Schematic figure of the structure of 06S061. (c) Outlook of 06S061 antenna.

subsidence meter. In addition, we observed groundwater level changes in the four groundwater monitoring wells of different depths inside GSI premises. A detailed description of the groundwater monitoring wells and the corresponding aquifers are given in Munekane et al. (2004).

\section{Quality Evaluation of $06 \mathrm{SO61}$}

\subsection{Comparison with independent observations}

We have evaluated the observation quality of GPS station 06S061 by comparing the GPS-derived vertical deformations of surrounding GPS stations relative to 06S061 with independent observations, i.e., those from the subsidence meter and leveling.

We first calculated the coordinate time series of surrounding GPS stations (Fig. 1(a)) with respect to 06S061 using GAMIT 10.35 (King and Bock, 2009) in the network mode. Two sets of solutions were obtained using different analysis strategies (Munekane et al., 2009), namely, (1) a shortdistance strategy in which we analyze GPS carrier phases independently at frequencies L1 and L2 in order to estimate baseline components only, and (2) a long-distance strategy in which we analyze ionosphere-free combinations of GPS carrier-phases at frequencies L1 and L2 in order to estimate tropospheric delays as well as baseline components.

In general, the short-distance strategy is more suitable than the long-distance strategy for the GPS analysis of short baselines $(\leq 10 \mathrm{~km})$, which is the case of the present analysis. For short baselines, noises on the carrier-phases, such

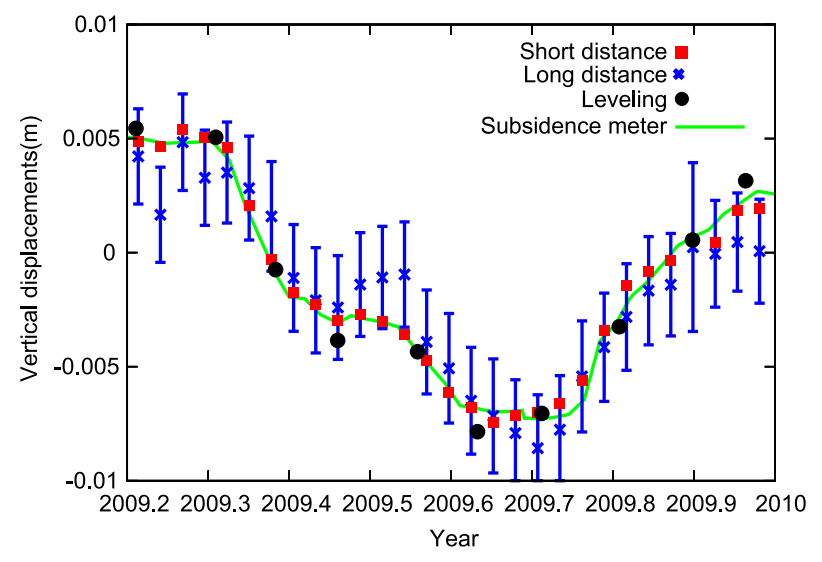

Fig. 2. Relative vertical deformations of 92110 relative to 06S061 obtained from GPS and measured by subsidence meter and leveling. Mean value over the entire period is removed from each time series. Error bars are given at the $1 \sigma$ level.

as ionospheric and tropospheric delays, will be common and canceled out at the both ends of the baselines. However, in the long-distance strategy, ionosphere-free combinations that are noisier than the original L1 and L2 carrier phases are analyzed to estimate tropospheric delays in addition to baseline components, introducing additional errors on the estimated baseline components. Nevertheless, we compared the results by using both strategies and evaluated the quality of 06S061 obtained using the long-distance strategy since the long-distance strategy is commonly employed in a regional/global GPS analysis.

We then compared the GPS-derived relative vertical deformations with corresponding observations of the subsidence meter and leveling. Note that the GPS-derived coordinate time series is averaged with a moving window of 10 days to suppress random noises and that the mean value over the entire period is removed from each time series. The vertical deformations of 92110 relative to $06 \mathrm{~S} 061$ derived from GPS and measured by the subsidence meter and leveling are shown in Fig. 2. One can see that they are in good agreement with each other for both strategies. In their original installation of 06S061, Munekane et al. (2009) pointed out that the GPS-derived relative vertical deformations were contaminated with spurious, large deviations in the longdistance strategy and that they suffered serious fluctuations in winter. On the contrary, the results after refurbishment do not demonstrate such spurious phenomena, owing to the substantial mitigation of errors.

Table 1 provides a summary of the differences between GPS solutions and measurements of the subsidence meter and leveling of relative vertical deformations of 92110 and 960627 with respect to $06 \mathrm{~S} 061$ and of the deviations of the GPS-derived vertical displacements of 960627 relative to 92110 about the mean value, as an indication of the observation quality of standard GPS stations. It is clear that the RMS and maximum amplitude differences between GPS solutions and the corresponding independent measurements of vertical deformations of 92110 and 960627 relative to 06S061 are comparable with the deviations in the GPS-derived vertical displacements of 960627 relative to 92110. 
Table 1. Differences in relative vertical deformations of 92110 and 960627 with respect to 06S061 between GPS solutions and measurements by the subsidence meter or leveling. Note that GPS solutions are averaged with a moving window of 10 days. The deviations about the mean in the GPS-derived vertical displacements of 960627 relative to 92110 are also given for comparison.

\begin{tabular}{|c|c|c|c|c|}
\hline & \multicolumn{2}{|c|}{ Short-distance strategy } & \multicolumn{2}{c|}{ Long-distance strategy } \\
\hline 92110 w.r.t. 06S061 & RMS difference $(\mathrm{m})$ & Max difference $(\mathrm{m})$ & RMS difference $(\mathrm{m})$ & Max difference $(\mathrm{m})$ \\
\hline Subsidence meter & 0.0004 & 0.0009 & 0.0014 & 0.0032 \\
\hline Leveling & 0.0014 & 0.0020 & 0.0019 & 0.0027 \\
\hline 960627 w.r.t. 06S061 & RMS difference $(\mathrm{m})$ & Max difference $(\mathrm{m})$ & RMS difference $(\mathrm{m})$ & Max difference $(\mathrm{m})$ \\
\hline Subsidence meter & 0.0011 & 0.0021 & 0.0020 & 0.0053 \\
\hline Leveling & 0.0012 & 0.0019 & 0.0017 & 0.0024 \\
\hline \hline 960627 w.r.t. 92110 & RMS dev $(\mathrm{m})$ & Max dev $(\mathrm{m})$ & RMS dev $(\mathrm{m})$ & Max dev $(\mathrm{m})$ \\
\hline & 0.0010 & 0.0016 & 0.0022 & 0.0049 \\
\hline
\end{tabular}

\subsection{Poroelastic deformations of aquifers below $190 \mathrm{~m}$}

We expect that $06 \mathrm{~S} 061$ is less affected by seasonal poroelastic deformations of aquifers since it is xed in the soil at a depth of $190 \mathrm{~m}$. However, it may still be affected, if at all, by the poroelastic deformations of aquifers below $190 \mathrm{~m}$. Hence, we should evaluate the magnitude of seasonal vertical deformations caused by such deformations.

Unfortunately, the coordinate time series of 06S061 is too short to extract seasonal poroelastic deformations of aquifers. Alternatively, we combined different types of observations to yield equivalent vertical coordinate time series of the vertical deformations caused by aquifers below $190 \mathrm{~m}$; we subtracted the vertical deformations of 06S061, measured by the subsidence meter, which are the thickness changes of the top soil up to a depth of $190 \mathrm{~m}$, from those of a nearby GPS station, TSKB. Hereafter, we refer to the obtained time series as the "GPS/Subsidence Meter" (GPS/SM) time series.

For this purpose, we rst analyzed GPS data at TSKB between 2005 and 2009. We used the GIPSY-OASIS II software (version 5.0) in the PPP mode (Zumberge et al., 1997) with the VMF1 mapping function and Zenith Hydrostatic Delays (ZTDs) from the European Centre for Medium Range Weather Forecasts (ECMWF) (Boehm et al., 2006). We have accounted for effects, such as atmospheric and ocean/hydrological loading and secondorder ionospheric delays. The details of the analysis are described in Munekane et al. (2010), but only the difference is applied for the ocean/hydrological loading data used; time series were obtained from Level-2 products of the Gravity Recovery And Climate Experiment (GRACE) (Tapley et al., 2004) processed at le Groupe de Recherche Geodesie Spatiale/Centre National d'Etudes Spatiales (GRGS/CNES) and linearly interpolated into the daily values from the original 10 -day values. We then corrected the estimated time series for vertical deformations measured by the subsidence meter to obtain the GPS/SM time series. A temporally linear trend was then estimated and removed from the time series to eliminate tectonicrelated movements.

We then attempted to extract the vertical deformations caused by poroelastic deformations of the aquifers below $190 \mathrm{~m}$ from the GPS/SM time series. We assumed that the poroelastic deformations of the aquifers at some depth are proportional to the water level changes of the corresponding well, as in Munekane et al. (2004), and estimated the admittances between them. In this process, there was one problem: there are no water level observations for the aquifers below $190 \mathrm{~m}$. Therefore, we assumed that water level changes of the well that corresponds to the aquifers below $190 \mathrm{~m}$ are similar to those of the 190-m-deep well that corresponds to the aquifers at a depth of about $140 \mathrm{~m}$ (Munekane et al., 2004). In order to account for the possible frequency-dependent phase shifts between them, we allowed time lags of up to 10 days between the water level changes of the 190-m-deep well and poroelastic deformations of the aquifers below $190 \mathrm{~m}$. We used the baytap08 software (Tamura et al., 1991; Tamura and Agnew, 2008) for this estimation.

The GPS/SM time series and the estimated poroelastic deformations of the aquifers below $190 \mathrm{~m}$ are shown in Fig. 3. The seasonal deformations having a peak-to-peak amplitude of about $1 \mathrm{~cm}$ are recognized in the GPS/SM time series. The RMS value of the GPS/SM time series is reduced from 0.0064 to $0.0055 \mathrm{~m}$ after removing the estimated poroelastic deformations. However, the residuals of the GPS/SM time series are still large and indicate some systematic variations.

\subsection{Multipath noise in GPS-derived vertical coordi- nates}

In order to determine if the large residuals in the previous section originate from the de ciency in the poroelastic models or the noise in the GPS observation, we investigated the effect of multipath on the GPS-derived coordinate time series since it is one of the signi cant noise sources that are not considered in a standard GPS analysis.

The effect of multipath may be evaluated using the receiver signal-to-noise ratio (SNR) (e.g. Bilich and Larson, 2007). We used the software snrprog (available at http:// www-gpsg.mit.edu/ tah/snrprog) to extract the phase delays caused by the multipath from the receiver SNR on a satellite-by-satellite basis. We then combined all of the data of each day to create a daily phase delay map on a $1^{\circ} \times 1^{\circ}$ grid using the nearest neighbor algorithm as implemented in the GMT software (Wessel and Smith, 1998).

We generated the simulated GPS data at TSKB using the SPSS software (e.g., Munekane et al., 2010) under the current satellite constellation with the addition of phase delays calculated from the daily phase delay maps. The generated data were analyzed using the GIPSY-OASIS II software to obtain the multipath-induced error time series.

In Fig. 4, we compared the multipath-induced error time 

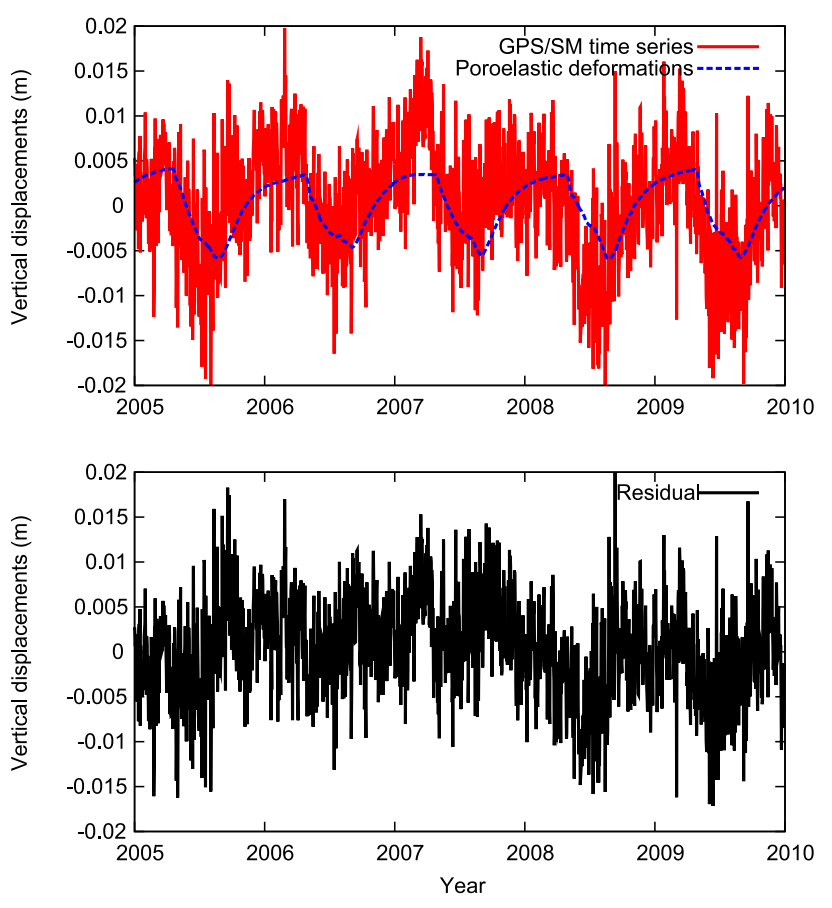

Fig. 3. (Top) GPS/SM time series and estimated poroelastic deformations of aquifers below $190 \mathrm{~m}$. (Bottom) Residuals of GPS/SM time series after subtracting poroelastic deformations.

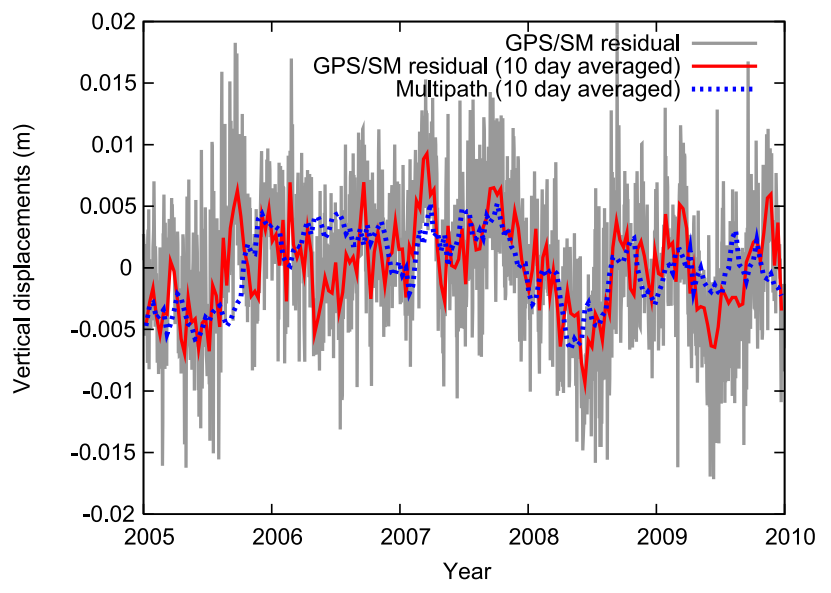

Fig. 4. Residuals of GPS/SM time series in Fig. 3 and estimated multipath-induced errors. Note that both time series are averaged with a moving window of 10 days.

series with the GPS/SM residual time series from the previous section. It can be clearly seen that both the series are in good agreement. The coherence between them is 0.50 .

\section{Discussion and Conclusions}

We first evaluated the observation quality of GPS station 06S061, which was installed to reduce the effect of seasonal vertical deformations associated with groundwater extraction. We compared the GPS-derived vertical deformations between 06S061 and the surrounding GPS stations with those measured by independent observations. As shown in Table 1, these are in good agreement; the RMS and maximum amplitude of the differences between GPS solutions and independent observations of the vertical movements of surrounding GPS stations relative to 06S061 have the same magnitude as the deviations in the GPS-derived vertical displacements between 92110 and 960627 . Therefore, we conclude that the refurbishment of 06S061 to overcome multipath from the roof and water droplets formed inside the radome (Munekane et al., 2009) worked as expected and that the observation quality of 06S061 has become comparable to that of standard GPS stations. The remaining differences between GPS solutions and independent observations of the short baselines might be due to multipath or phase center model errors at either stations. Further study to quantitatively evaluate these errors (e.g. King and Williams, 2009) will help improve the observation quality of the GPS stations.

We then estimated the seasonal deformations due to poroelastic deformations of the aquifers below $190 \mathrm{~m}$ from the equivalent GPS/SM time series. As shown in Fig. 3, the estimated poroelastic deformations have a peak-to-peak amplitude of about $1 \mathrm{~cm}$. Originally, the vertical coordinate time series of surface GPS stations in Tsukuba show seasonal vertical deformations with a peak-to-peak amplitude of about $2 \mathrm{~cm}$ (Munekane et al., 2004) and, accordingly, the observation of 06S061 will contain only half of the entire seasonal vertical deformations caused by groundwater extraction.

Our poroelastic model, which accounts for the deformations of aquifers below $190 \mathrm{~m}$, are based on one fundamental assumption: the supposed water level changes of the well that corresponds to the aquifers below a depth of $190 \mathrm{~m}$ are similar to those of the 190-m-deep well with aquifers at about $140 \mathrm{~m}$. We have checked this assumption by comparing the water level changes of the 190-m-deep well with those of the 300-m-deep well at the National Institute of Advanced Industrial Science and Technology (AIST) located $6 \mathrm{~km}$ south of GSI, which corresponds to the aquifers at a depth of about 230-270 m (Ohtani et al., 2008). The analysis shows a significantly high coherence of water level changes between the two time series $(\sim 0.92)$. We conclude that the water level changes of the 190-m-deep well are similar to those of the wells that correspond to deeper $(>190 \mathrm{~m})$ aquifers, and therefore, that our assumption is valid.

We observed a high correlation between the residual GPS/SM time series obtained by subtracting the estimated poroelastic deformations and the simulated multipathinduced error time series, as shown in Fig. 4. This high correlation confirms that the large residuals observed in the GPS/SM time series are not due to the deficiency of the poroelastic model but due to the multipath-induced noise in the original vertical coordinate time series of TSKB.

The mechanisms generating the time-correlated multipath-induced errors as seen in Fig. 4 are not fully understood. Using numerical simulations, King and Watson (2010) showed that even time-constant multipath effects can result in time-correlated multipath-induced errors under time-variable GPS geometry, as seen in reality. It is also probable that time-variable surface reflectivity changes due to soil moisture (Larson et al., 2010) or vegetation growth (Small et al., 2010) cause temporal changes in the multipath effects and hence result in timecorrelated multipath-induced errors. Since the magnitude of the multipath-induced errors is large (about $1 \mathrm{~cm}$ in 
peak-to-peak values), it is necessary to identify its causes and eliminate them.

Acknowledgments. We acknowledge Y. Ohta and one anonymous reviewer for constructive comments which helped improve the manuscript. We would thank M. Nakamura and N. Matsumoto of AIST for providing us the groundwater level data. We are indebted to Y. Tamura and D. C. Agnew for baytap08, and T. Herring for snrprog. We are also grateful to the GRGS/CNES for making their GRACE products freely available.

\section{References}

Altamimi, Z., X. Collilieux, J. Legrand, B. Garayt, and C. Boucher, ITRF2005: a new release of the International Terrestrial Reference Frame based on time series of station positions and earth orientation parameters, J. Geophys. Res., 112, B09401, doi:10.1029/2007JB004949, 2007.

Bilich, A. and K. M. Larson, Mapping the GPS multipath environment using the signal-to-noise ratio (SNR), Radio Sci., 42, RS6003, doi:10.1029/2007RS003652, 2007.

Boehm, J., B. Werl, and H. Schuh, Troposphere mapping functions for GPS and very long baseline interferometry from European Centre for Medium-Range Weather Forecasts operational analysis data, J. Geophys. Res., 111, B02406, doi:10.1029/2005JB003629, 2006.

King, R. W. and Y. Bock, Documentation for the GAMIT GPS Analysis Software Release 10.35, Massachusetts Institute of Technology, Cambridge, USA, 2009.

King, M. A. and C. S. Watson, Long GPS coordinate time series: multipath and geometry effects, J. Geophys. Res., 115, B04403, doi:10.1029/2009JB006543, 2010.

King, M. A. and S. D. P. Williams, Apparent stability of GPS monumentation from short-baseline time series, J. Geophys. Res., 114, B10403, doi:10.1029/2009JB006319, 2009.

Larson, K. M., J. J. Braun, E. E. Small, V. U. Zavorotny, E. D. Gutmann, and A. L. Bilich, GPS multipath and its relation to near-surface soil moisture content, IEEE J. Sel. Topics Appl. Earth Obs. Remote Sens., 3, 91-99, doi:10.1109/JSTARS.2009.2033612, 2010.

Munekane, H. and J. Boehm, Numerical simulation of troposphereinduced errors in GPS-derived geodetic time series over Japan, J. Geod.,
84(7), 405-417, doi:10.1017/s00190-010-0376-4, 2010.

Munekane, H., M. Tobita, and K. Takashima, Groundwater-induced vertical movements observed in Tsukuba, Japan, Geophys. Res. Lett., 31, L12608, doi:10.1029/2004GL020158, 2004.

Munekane, H., Y. Kuroishi, Y. Hatanaka, K. Takashima, M. Ishimoto, and M. Tobita, An ultra-deeply anchored GPS station in Tsukuba, Japan preliminary report-, Bull. Geogr. Surv. Inst., 57, 11-17, 2009.

Ohtani, R., N. Koizumu, M. Takahashi, N. Matsumoto, T. Sato, Y. Kitagawa, and S. Itaba, The variation of the groundwater level, discharge rate tilt meter three-component strain, and subsidence in the Tokai, Kanto district and Izu peninsula, Central Japan (from November 2007 to April 2008)(37), Rep. Coord. Comm. Earthquake Prediction, 80, 360368, 2008 (in Japanese).

Small, E. E., K. M. Larson, and J. J. Braun, Sensing vegetation growth with re ected GPS signals, Geophys. Res. Lett., 37, L12401, doi:10.1029/2010GL042951, 2010.

Tamura, Y. and D. C. Agnew, Baytap08 user's manual (available at http://escholarship.org/uc/item/4c27740c), Scripps Institution of Oceanography, San Diego, 2008.

Tamura, Y., T. Sato, M. Ooe, and M. Ishiguro, A procedure for tidal analysis with a Bayesian information criterion, Geophys. J. Int., 104, 507-516, 1991.

Tapley, B. D., S. Bettadpur, J. C. Ries, P. F. Thompson, and M. M. Watkins, GRACE measurements of mass variability in the Earth system, Science, 305(5683), 503-506, 2004.

Tobita, M., H. Munekane, M. Kaidzu, S. Matsuzaka, Y. Kuroishi, Y. Masaki, and M. Kato, Seasonal variation of groundwater level and ground level around Tsukuba, J. Geod. Soc. Jpn., 50, 27-37, 2004 (in Japanese with English abstract).

Wessel, P. and W. H. F. Smith, New, improved version of Generic Mapping Tools released, Eos. Trans. AGU, 79(47), 579, 1998.

Zumberge, J. F., M. B. He in, D. C. Jefferson, M. M. Watkins, and F. H. Webb, Precise point positioning for the ef cient and robust analysis of GPS data from large network, J. Geophys. Res., 102(B3), 5005-5018, 1997.

H. Munekane (e-mail: munekane@gsi.go.jp), Y. Kuroishi, Y. Hatanaka, K. Takashima, and M. Ishimoto 